\title{
ANALISIS SISTEM PENGUKURAN GETARAN MEMS ACCELEROMETER ADXL345
}

\author{
Indra Feriadi ${ }^{1}$, Fajar Aswin ${ }^{2}$, M. Iqbal Nugraha ${ }^{3}$ \\ 1,2 Jurusan Teknik Mesin - Politeknik Manufaktur Negeri Bangka Belitung \\ 3 Jurusan Teknik Elektro dan Informatika - Politeknik Manufaktur Negeri Bangka Belitung \\ Telp.0717-93586, Fax.0717-93585, indra@polman-babel.ac.id
}

\begin{abstract}
Vibration measurement technology using conventional sensors such as piezoelectric (PZT) Accelerometer is still expensive. Currently, many low-cost vibration measuring devices have been developed by using Micro Electro Mechanical System (MEMS) technology. This study aims to analyze the results of vibration measurement system MEMS Accelerometer ADXL345 with PZT Accelerometer. This research applies design and develop approach with comparative data analysis technique, that is comparing data of result of measurement of MEMS Accelerometer ADXL345 to PZT Accelerometer Vibroport80. The construction comprises the ADXL345 sensor connected to the Arduino Mega 2560 microcontroller operated by Widows operating system and programming language Arduino IDE 1.08. Testing of measurements at Bearing speeds of 500, 1000, and 1500 RPM with length of time measurements at 5, 10, and 20 seconds respectively. The analysis of the test results shows that the MEMS Accelerometer ADXL345 of vibration measurement system can measure, process and display vibration measurement data larger 3\% than PZT Accelerometer and can provide the best measurement accuracy at 20 seconds measurement length of time.
\end{abstract}

Keywords: Measurement, Vibration, MEMS Accelerometer, ADXL345, Arduino Mega 2560.

\begin{abstract}
Abstrak
Teknologi mengukur getaran menggunakan sensor konvensional seperti piezoelectric (PZT) Accelerometer masih cukup mahal, kira-kira sepuluh kali lebih dari accelerometer tipe PZT [3]. Dewasa ini telah banyak dikembangkan alat pengukur getaran berbiaya rendah menggunakan teknologi Micro Electro Mechanical System (MEMS). Peneltian ini bertujuan untuk menganalisis hasil sistem pengukur getaran MEMS Accelerometer ADXL345 dengan Piezoelectic Accelerometer. Penelitian ini menggunakan pendekatan rancang bangun alat dengan teknik analisis data komparatif, yaitu membandingkan data nilai hasil pengukuran sensor sensor ADXL345 dengan Piezoelectric. Konstruksi alat yang dibuat terdiri dari sensor ADXL345 yang diletakkan dalam Housing terhubung dengan mikrokontroler Arduino Mega 2560 yang dijalankan dengan sistem operasi Widows dan diprogram dengan bahasa pemrograman Arduino IDE 1.08. Pengujian pengukuran pada kecepatan putaran Bearing 500, 1000, dan 1500 RPM dengan lama waktu pengukuran masing-masing 5, 10, dan 20 detik. Analisis terhadap hasil pengujian menunjukkan bahwa sistem pengukuran getaran MEMS Accelerometer ADXL345 dapat mengukur, mengolah dan menampilkan data getaran hasil pengukuran lebih besar 3 persen dari Piezoelectric Accelerometer dan memberikan akurasi pengukuran terbaik pada lama waktu pengukuran 20 detik.
\end{abstract}

Kata kunci: Pengukuran, Getaran, MEMS Accelerometer, ADXL345, Arduino Mega 2560.

\section{PENDAHULUAN}

1.1 Latar Belakang

Pemantauan getaran yaitu memeriksa dan mengukur parameter getaran secara rutin dan terus menerus. Getaran pada mesin dapat terjadi karena adanya kerusakan pada poros, bantalan, roda gigi, kurang kencangnya sambungan, kurang lancarnya pelumasan, kurang tepatnya pemasangan transmisi dan juga disebabkan karena ketidakseimbangan elemen mesin yang berputar. Kerusakan-kerusakan seperti ini akan menimbulkan getaran yang cukup besar. Dengan mengukur getaran yang terjadi, kerusakan mesin dapat dideteksi secara dini dan akhirnya kerusakan yang lebih jauh dapat dicegah. 
Banyak teknik yang telah tersedia dipasaran untuk mengukur dan menganalisa getaran mesin, namun membutuhkan sumber daya yang mahal untuk mengidentifikasi masalah kerusakan pada mesin. Umumnya peralatan yang mahal tersebut tersebut menggunakan sensor-sensor konvensional seperti sensor eddy-current, sensor swing coil velocity dan sensor piezoelectric accelerometer untuk melakukan pengukuran getaran [1]. Untuk mengatasi masalah biaya mahal, dewasa ini telah banyak dikembangkan alat pengukur getaran berbiaya rendah dengan menggunakan sensor dengan teknologi Micro Electro Mechanical System (MEMS). Dengan teknologi ini, biaya yang dibutuhkan kira-kira sepersepuluh dari accelerometer tipe PZT [3]. Teknologi Micro Electro Mechanical System (MEMS) adalah suatu sistem mikro dengan kemampuan fungsi elektromekanik baik sebagai mikrosensor maupun microactuator [2]. Sensor MEMS akselerometer merupakan sensor yang mempunyai teknologi MEMS dengan prinsip kerja yang sama dengan sensor konvensional. Sensor jenis ini bukan merupakan sensor yang umum digunakan dalam pengukuran getaran pada industri.

Beberapa penelitian yang terkait dengan penggunaan teknologi MEMS antara lain: Swathy. L dan Lizy Abraham (2014), meneliti sistem pemantauan getaran memanfaatkan teknologi MEMS dengan sensor ADXL345 tiga sumbu dan AT Mega Microcontroller dengan perangkat lunak Labviews untuk penerapan di pesawat ruang angkasa. Hasil penelitian tersebut menunjukkan bahwa sensor MEMS digital ADXL345 secara konsisten memantau sinyal getaran yang berbeda dengan akurasi yang baik; Chih-Yung Huang and Jian-Hao Chen (2016) mengembangkan penggunaan sensor MEMS accelerometer dua sumbu ADXL001, kartu akuisisi data NI 9234, dan perangkat lunak Labvies untuk memantau getaran mesin perkakas dengan hasil nilai pengukuran dalam domain waktu akselerometer MEMS lebih besar dari pada akselerometer PZT kurang dari 6 persen [3]; J. Selvakumar and A. Edwin Prakash (2016) menggunakan sensor MEMS Accelerometer dengan sistem akuisisi data LABJACK U3 yang terhubung Raspberry Pi-2 CPU yang dioperasikan dengan sistem operasi LINUX dan bahasa pemrograman Python untuk mengukur getaran bantalan [4]. Penelitian ini menghasilkan sistem pengukuran sederhana yang hemat biaya untuk industri skala kecil/menengah dan teknik presentasi data untuk mengidentifikasi kesalahan komponen bantalan dengan mudah.

Penelitian ini bertujuan untuk membuat dan menganalisis sistem pengukur getaran berbiaya rendah dengan menggunakan sensor MEMS Accelerometer ADXL345, dan Mikrocontroller Arduino Mega 2560 yang dijalankan dengan sistem operasi Widows dan diprogram dengan Arduino IDE 1.08. Analisis hasil pengukuran dilakukan dengan membandingkannya dengan nilai pengukuran alat pembanding berupa sensor piezoelectric accelerometer Vibroport80.

\section{METODA PENELITIAN}

\subsection{Tahapan Penelitian}

Penelitian dilakukan dalam tiga tahapan sebagai berikut: 1. Tahap Awal: Pengumpulan data dan penentuan disain penelitian; 2. Tahap perancangan dan pembuatan alat media uji (Bearing Kit) dan alat pengukur getaran MEMS Accelerometer ADXL345; 3. Tahap Akhir: Pengujian sistem pengukuran getaran MEMS Accelerometer ADXL345 dan Analisis hasil pengujian ADXL345 dengan Piezoelectric.

\subsection{Desain Ekperimen}

1) Disain eksperimen sistem pengukuran dan akuisisi data getaran terdiri dari media uji dan alat pengukur getaran seperti ditunjukkan pada gambar 1 , desain sistem pengukuran pada gambar 2 , dan experimental setup pada gambar 3.

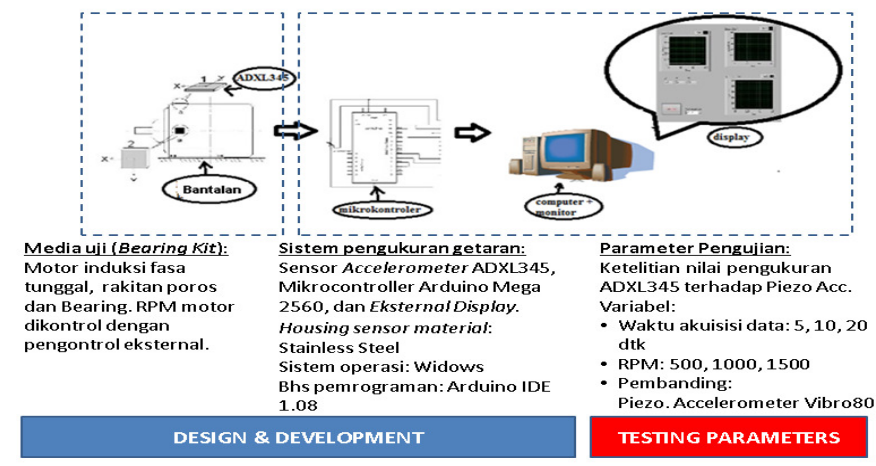

Gambar 1. Disain Eksperimen 
Gambar 2 menunjukkan disain sistem pengukuran getaran yang terdiri dari Bearing kit dan alat pengukur getaran yang terdiri dari Accelormeter ADXL345, Microcontroller, dan komputer penampil data.

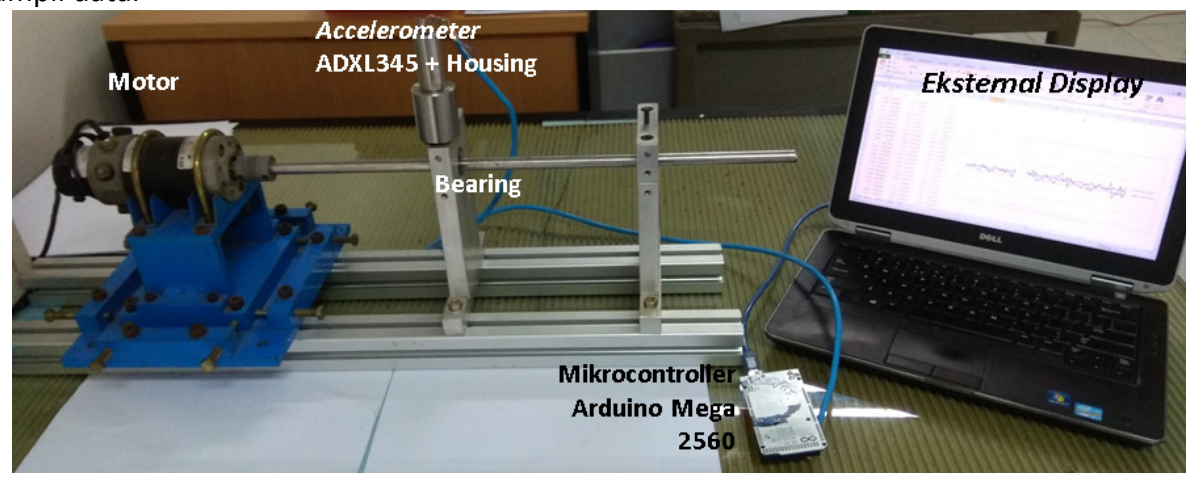

Gambar 2. Disain Sistem Pengukuran Getaran

Gambar 3 menunjukkan Experimental Setup Sistem Pengukuran dan Akuisisi Data Getaran yang terdiri dari Bearing kit, alat pengukur getaran ADXL 345 dan accelerometer pembanding (Piezoelectric) beserta alat pengukur dan diagnostik Vibroport80.

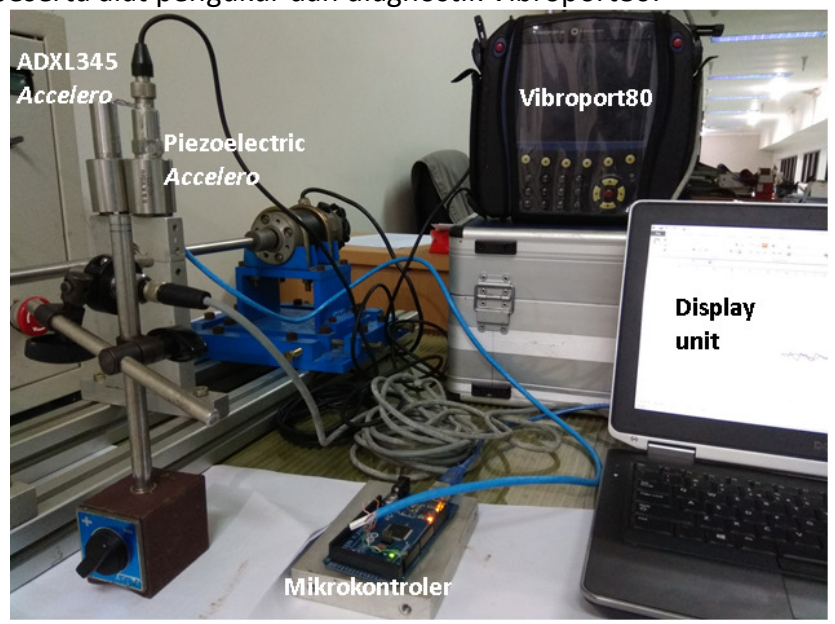

Gambar 3. Experimental Setup Sistem Pengukuran dan Akuisisi Data Getaran

Sensor Accelerometer ADXL345 dan Piezoelectric Vibroport 80 dipasang pada bagian yang paling dekat dengan Bearing; Perintah mulai mengakuisisi data melalui perangkat lunak Arduino IDE 1.08 dikirim ke mikrokontroler untuk memulai pengambilan data; Bersamaan dengan perintah mulai ambil data pada ADXL345, vibroport 80 disetting juga untuk pengambilan data dengan parameter Time Signal dengan frekuensi $10 \mathrm{KHz}$ dan low pass filter pada frekuensi $50-60 \mathrm{~Hz}$ (sebagai filter noise frekuensi listrik); Setelah mendapatkan data initial, algoritma program pada mikrokontroler dimodifikasi dengan perintah penjumlahan atau pengurangan berdasarkan hasil pengukuran awal; Hasil program modifikasi kemudian dikirim (upload) ke memori mikrokontroler untuk selanjutnya dieksekusi; Mikrokontroler memproses data dari sensor untuk kemudian dikirimkan ke Komputer untuk ditampilkan.

2) Pengubah yang diukur/diamati

Data-data yang digunakan pada penelitian ini merupakan data primer yang diperoleh langung dari hasil eksperimen. Peubah yang diamati/diukur adalah tingkat ketelitian akselerasi hasil pengukuran alat yang diuji dibandingkan dengan alat pembanding. Tipe alat pembanding sebagai peubah bebas sedangkan peubah penyerta terdiri dari:

a. Lama waktu akuisisi data pada 5 detik, 10 detik dan 20 detik.

b. Kecepatan putaran motor pada 500, 1000, dan 1500 RPM. 


\section{HASIL DAN PEMBAHASAN}

Pengujian dilakukan dengan mengukur getaran Bearing pada kecepatan putaran 500, 1000, dan 1500 RPM dengan masing-masing lama waktu pengukuran selama 5 detik, 10 detik dan 20 detik. Data rata-rata nilai hasil pengujian sebagaimana ditunjukkan pada Tabel 1 dan gambar 4 dan 5 .

Tabel 1. Data Hasil Pengujian

\begin{tabular}{|c|c|c|c|c|c|c|c|c|c|c|c|c|}
\hline \multirow{2}{*}{$\begin{array}{l}\text { Waktu } \\
\text { (Detik) }\end{array}$} & \multicolumn{4}{|c|}{500 RPM } & \multicolumn{4}{|c|}{1000 RPM } & \multicolumn{4}{|c|}{1500 RPM } \\
\hline & $\begin{array}{c}A D X \\
L\end{array}$ & $\begin{array}{c}\text { Vibr } \\
0\end{array}$ & Deviasi & $\%$ Dev & $\begin{array}{c}\mathrm{ADX} \\
\mathrm{L}\end{array}$ & $\begin{array}{c}\text { Vibr } \\
0\end{array}$ & Deviasi & $\%$ Dev & $\begin{array}{c}A D X \\
L\end{array}$ & $\begin{array}{c}\text { Vibr } \\
0\end{array}$ & Deviasi & $\%$ Dev \\
\hline 5 & 0,22 & 0,19 & 0,03 & 3,02 & 0,27 & 0,24 & 0,03 & 3,21 & 0,44 & 0,40 & 0,04 & 3,68 \\
\hline 10 & 0,22 & 0,19 & 0,03 & 3,02 & 0,27 & 0,24 & 0,03 & 2,56 & 0,44 & 0,41 & 0,04 & 3,59 \\
\hline 20 & 0,22 & 0,19 & 0,03 & 3,02 & 0,27 & 0,25 & 0,03 & 2,53 & 0,45 & 0,42 & 0,03 & 2,90 \\
\hline Rata2 & 0,22 & 0,19 & 0,03 & 3,02 & 0,27 & 0,24 & 0,03 & 2,77 & 0,44 & 0,41 & 0,03 & 3,39 \\
\hline
\end{tabular}

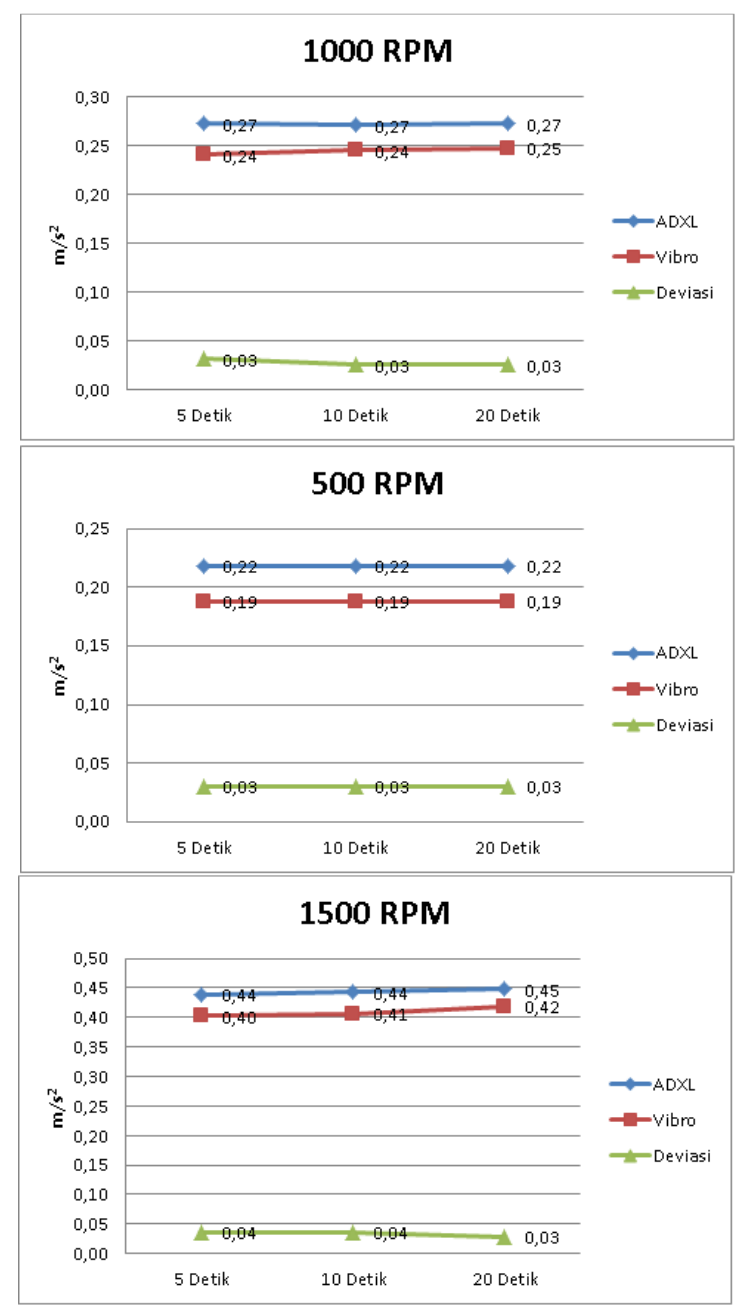

Gambar 4. Grafik Hasil Pengukuran Getaran MEMS Accelerometer ADXL345

Grafik di atas menggambarkan posisi garis grafik hasil pengukuran MEMS Accelerometer ADXL345 pada 3 kecepatan putaran selalu berada di atas garis grafik alat pembanding (Piezoelectric Accelerometer vibroport 80 ) dan terdistribusi relatif hampir merata pada 3 jenis waktu pengukuran. Hal ini mengindikasikan bahwa nilai pengukuran yang terjadi lebih besar $0,03-0,04 \mathrm{~m} / \mathrm{s}^{2}$ atau $3 \%$ dari PZT 
Accelerometer Vibro80. Nilai ini masih lebih rendah dibandingkan dengan hasil penelitian [3] yang mendapatkan nilai pengukuran MEMS Accelerometer lebih besar dari PZT accelerometer kurang dari $6 \%$. Hasil pengujian ini juga menunjukkan bahwa pada kecepatan 1500 RPM, kedua alat menunjukkan terjadi kenaikan getaran yang cukup besar, yaitu rata-rata hampir sebesar $0,2 \mathrm{~m} / \mathrm{s}^{2}$.

Hasil pengujian juga menunjukkan bahwa semakin lama waktu pengukuran maka kecenderungan terjadi penurunan deviasi hasil pengukuran MEMS Accelerometer ADXL345 sebagaimana ditunjukkan pada gambar 5. Dimana pada waktu 5 detik rata-rata 3,30\%, waktu 10 detik rata-rata 3,06\%, dan pada waktu 20 detik rata-rata sebesar 2,81\%. Hal ini mengindikasikan bahwa semakin lama waktu melakukan pengukuran maka akurasi pengukuran semakin baik.

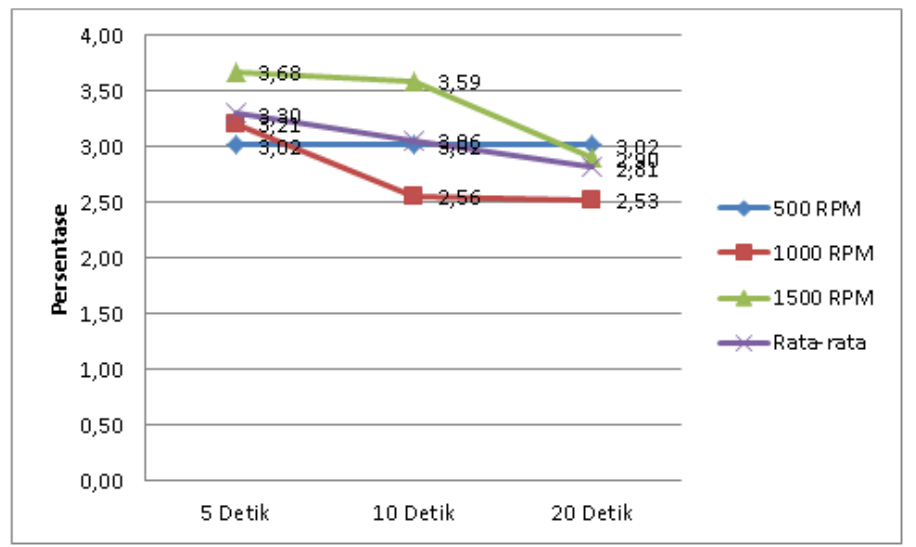

Gambar 5. Akurasi Hasil Pengukuran ADXL345 terhadap Lama Waktu Pengukuran

\section{SIMPULAN}

Penelitian ini menghasilkan sistem pengukuran getaran yang sederhana dimana dengan menggunakan sensor Accelerometer ADXL345, pemroses data Mikrokontroler Arduino Mega 2560 serta perangkat lunak Arduino IDE 1.08 dapat mengukur dan menampilkan data getaran pada kecepatan putaran yang berbeda-beda dengan hasil pengukuran lebih besar 3\% dari PZT Accelerometer dan dapat memberikan akurasi hasil terbaik pada lama waktu pengukuran 20 detik.

\section{DAFTAR PUSTAKA}

[1]. Broch, Jens Trampe, Mechanical Vibration and Shock Measurements. 2nd Ed. Soborg: K. Larsen \& Son, 1985.

[2]. L, Swathy. Lizy Abraham, "Vibration Monitoring Using MEMS Digital Accelerometer with Atmega and LabVIEW Interface for Space Application", International Journal of Innovative Science, Engineering \& Technology. Vol. 1, 2014.

[3]. Chih-Yung Huang and Jian-Hao Chen, "Development of Dual-Axis MEMS Accelerometers for Machine Tools Vibration Monitoring", Jurnal Appled Science, 6, 201; doi:10.3390, 2016.

[4]. J. Selvakumar and A. Edwin Prakash, "Data Acquisition System and Signal Processing Technique for Bearing Fault Analysis", Indian Journal of Science and Technology, Vol 9(31), DOI: 10.17485/ijst/2016/v9i31/92769, August 2016. 